\title{
The Influence of Retinal Afferents Upon the Development of Layers in the Dorsal Lateral Geniculate Nucleus of Mustelids ${ }^{1}$
}

\author{
R. W. GUILLERY, ${ }^{2}$ A. S. LAMANTIA, ${ }^{3}$ J. A. ROBSON, ${ }^{*}$ AND K. HUANG \\ Committee on Neurobiology and Department of Pharmacological and Physiological Sciences, The University of Chicago, \\ Chicago, Illinois 60637 and *Department of Anatomy, State University of New York, Upstate Medical Center, Syracuse, New York 13210
}

\begin{abstract}
The extent to which the development of a normal laminated lateral geniculate nucleus depends upon retinal afferents has been studied in normal and albino ferrets and in mink. Removal of all retinal afferents before they invade the nucleus (28 days in utero) or before they establish distinct monocular terminal fields (newborn, $\sim 41$ days post-conception) produces a nuleus that is smaller than normal and poorly separated from the adjacent perigeniculate and medial interlaminar nuclei. However, the nucleus is wedge-shaped, resembling a normal adult nucleus, in which a broad medial binocular segment is distinguishable from a narrower lateral monocular segment. There is a normal mediolateral gradient of cell sizes and some signs of a laminar differentiation, cells next to the optic tract being morphologically distinguishable from cells near the optic radiation, but no cell-free interlaminar zones are formed.
\end{abstract}

The development of a monocularly innervated nucleus depends on the size of the surviving retinal input. In normally pigmented ferrets or mink the crossed retinofugal component is larger than the uncrossed component. In the monocular animals one sees essentially a monocular set of geniculate layers on each side, with an appropriate asymmetry. Each nucleus can be regarded as representing the survival of those layers which would have been innervated by the good eye, together with some additional geniculate territory that appears to be added to the surviving layers as retinogeniculate axons occupy territory normally innervated by the other eye. The crossed component of an albino ferret is abnormally large and the monocularly innervated contralateral nucleus is almost like that of a normal albino. There is a full complement of geniculate layers and interlaminar zones, which appears to develop without any binocular interactions. The ipsilateral retinogeniculate component of albinos is extremely small. In the monocular albino animals it forms discontinuous terminal patches, leaving sectors of the poorly differentiated nucleus uninnervated.

These results show that in geniculate development there is a limited interaction between the two sets of retinal affer-

Received August 17, 1984; Revised November 16, 1984;

Accepted November 27, 1984

1 This work was supported by National Institutes of Health Grants EY 02374, EY 03490, and NS 14283, and by the Alfred P. Sloan Foundation.

${ }^{2}$ To whom correspondence should be sent, at his present address: Department of Human Anatomy, South Parks Road, Oxford, OX1 3QX, England.

${ }^{3}$ Present address: Section of Neuroanatomy, Yale University School of Medicine, 333 Cedar Street, New Haven, CT 06510. ents. Each set plays a well defined and distinctive role, and one can replace the other to a limited extent only.

In many mammals the dorsal lateral geniculate nucleus shows a well marked laminar arrangement of cells and fibers. Several layers are distinguishable on the basis of their structure, connections, and function, and these layers can be categorized in a number of different ways. Some of the layers correspond to a segregation of crossed from uncrossed retinal afferents. Others correspond to a separation of functionally distinct retinal afferents, which may be a separation of on-center from off-center cells (Schiller and Malpeli, 1978; LeVay and McConnel, 1982; Conway and Schiller, 1983; Stryker and Zahs, 1983) or a separation of "X-like," "Y-like," or "Wlike" cells from one another (see Rodieck, 1979; Stone et al., 1979; Lennie, 1980; Sherman and Spear, 1982). In addition, there are some relatively cell-free interlaminar zones, receiving no relinal afferents but rich in nonretinal afferents (Guillery, 1969, 1979; Sanderson and Kaas, 1974; Mason and Robson, 1979; Wilson and Hendrickson, 1981).

The extent to which the development of this laminar arrangement depends on the presence of retinal inputs has been partially defined for some species. Brunso-Bechtold and Casagrande (1981) have shown that in tree shrews, removal of all retinal afferents at an early stage of development halts futher laminar differentiation, especially of the interlaminar zones, although some characteristic maturation of the geniculate cells continues. Rakic (1981), who has studied the effects of very early, prenatal, monocular deafferentation in macaque monkeys, has shown that some laminar distinctions survive, as do some interlaminar zones, but that others fail to develop.

We have used ferrets and mink, which have a well differentiated laminated lateral geniculate nucleus, to study the aspects of geniculate lamination that can develop with no retinal inputs, the aspects that are dependent on a monocular input, and those that may be dependent for their development upon a binocular input. The mustelids were chosen for three reasons. (1) They have a nucleus with well defined laminae basically like those of the better studied cat (Sanderson, 1974); however, there is an extra set of layers, which serves to separate on-center from off-center cells (LeVay and McConnel, 1982; Stryker and Zahs, 1983). (2) Ferrets and mink are born at a very early developmental stage, before there is any sign of geniculate lamination and while the afferents from the two eyes are still entirely overlapping in the nucleus (Linden et al., 1981). (3) It is relatively easy to obtain albino ferrets. In the albinos, most of the retinofugal fibers are crossed (Guillery, 1971; Cucchiaro and Guillery, 1984), so that removal of one eye leaves one lateral geniculate almost entirely devoid of geniculate afferents and the other only slightly affected. The mink and the ferret are very much alike (Sanderson, 1974; Sanderson et al., 1974; Linden et al., 1981), but since the laminar pattern in the lateral geniculate is somewhat clearer and more readily illustrated in the mink we have used a mink 
in order to show the laminar arrangements most clearly. Since ferrets are easier to obtain and to keep, we have used them for most of the experiments.

\section{Materials and Methods}

Monocular or binocular enucleations were done on the day of birth, and in some of the ferrets binocular enucleations were done on the 28th or 29th day of gestation. The newborn animals were immobilized by cooling, the eye was removed whole so that the cut optic nerve could be identified, and the opening was closed by a single suture. For the intrauterine enucleations the pregnant female ferret was anesthetized with xylazine, ketamine, and sodium pentobarbital; the uterus was exposed, a part of its surface was treated with local anesthetic, and then a purse-string suture was placed through the uterine wall over the region of the fetal head. An incision was made inside the loop of the suture, the head was briefly exposed (the suture being gently tightened to prevent complete emergence of the fetus), the eyes were removed, the fetus was returned to the uterine cavity, and the suture was closed. Precautions were taken to maintain sterility and antibiotic treatment was given. The female ferret was allowed to recover and at term ( 41 days), the experimental animals were delivered by Caesarian section, generally for adoption by another female.

When the experimental animals were 4 weeks old or older (see "Results"), they were anesthetized with sodium pentobarbital and perfused through the heart with either $10 \%$ formal saline or a mixture of $1.5 \%$ paraformaldehyde and $1.5 \%$ glutaraldehyde in a $0.1 \mathrm{M}$ phosphate buffer. In some of the monocular animals an injection of 4 to $10 \mu \mathrm{l}$ of $\left[{ }^{3} \mathrm{H}\right]$ proline $(200$ to $1000 \mu \mathrm{Ci})$ in saline was made into the surviving eye 1 to 14 days before death. The brains were cut as frozen or paraffin sections in the horizontal plane. Some of the sections ( 1 in 3 or 1 in 6) were prepared as a Nissl series with cresyl violet, and others were prepared as autoradiographs (Rogers, 1979) where appropriate.

\section{Results}

\section{The normal nucleus}

The normal cellular structure of the lateral geniculate nucleus of mink and ferrets and the laminar distribution of the retinal afferents have been described previously (Sanderson, 1974; Sanderson et al., 1974; Guillery and Oberdorfer, 1977; Linden et al., 1981). Figure 1 shows that in its basic structure the nucleus is like that of the domestic cat (see Guillery, 1970; Hickey and Guillery, 1974). However, there are some differences that are important for this study. The generic " $A$ " layers, layers $A$ and $A 1$, are each made up of two distinct leaflets. The separation of these leaflets is clearer in mink than in ferrets and in each species is better defined in lamina A than in A1. In a Nissl preparation, the ferret's leaflets are not always easily seen (see Fig. 6), but they are generally demonstrable when the

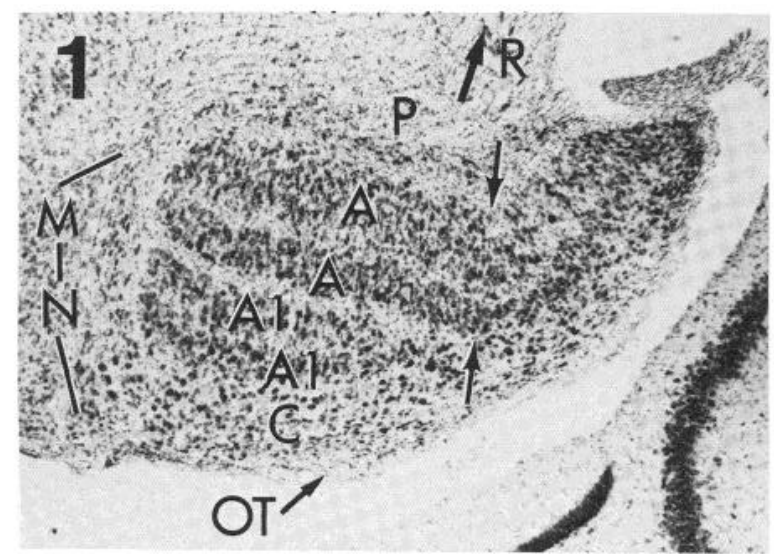

Figure 1. Horizontal section through the dorsal lateral geniculate nucleus of a normal mink; Nissl preparation. Rostral $(R)$ is indicated by the top arrow; medial is to the left. $A$ and $A 1$ indicate the leaflets of the generic $A$ layers; $C$ indicates the magnocellular $C$ layer; $M I N$ indicates the medial interlaminar nucleus. The monocular segment of the nucleus is the region to the right of the arrows, extending beyond the lateral border of layer A1. OT, optic tract; $P$, perigeniculate nucleus. Magnification $\times 26$. retinal afferents are labeled autoradiographically, or with horseradish peroxidase.

In the mustelids, the monocular segment, represented by the parts of the $A$ and $C$ layers extending beyond the lateral margin of layer $\mathrm{A} 1$ (the region to the right of the arrows in Fig. 1), is relatively larger than it is in the cat, and the parvocellular layers are generally thicker. The perigeniculate nucleus (Fig. 1, p) is also relatively larger in the ferret and mink than in the cat. It almost forms an additional layer next to lamina A, but it is clearly separated from this layer by the fibers of the optic radiation. The medial interlaminar nucleus (MIN in Fig. 1), like that of the cat, is easily recognized as a distinct, triangular cell group, continuous with the several C layers posteriorly, but clearly separated anteriorly from the A layers by a cell-free zone. Within the lateral geniculate nucleus there is a gradient of cell size for each layer, the cells in the medial and caudal, binocular parts being largest, and those at the rostral and lateral, monocular tip being smallest.

\section{The nucleus after complete removal of retinal afferents}

Figures 2 to 5 show the geniculate structures that develop in ferrets after an early binocular enucleation. The enucleations done on either the 28th to 29th days of gestation (three animals) or at birth (six animals) produced essentially the same result even though the retinofugal fibers are at quite different stages of development at the two ages (Cucchiaro and Guillery, 1984). At 28 days the retinal fibers have reached the nucleus but barely invaded it and the nucleus itself is represented by only a narrow band of cells. By birth the nucleus is quite well formed and occupied throughout its whole extent by crossed and uncrossed fibers (Linden et al., 1981). Figures 2 to 5 show the nucleus as it appears 4 weeks after birth, and Figure 6 shows a normal nucleus at the same age for comparison. Although there is some slight further differentiation of the normal nucleus after the fourth postnatal week (see Linden et al., 1981), our material shows no significant changes in the binocularly enucleated animals.

In the experimental animals the nucleus is smaller than normal and does not have its characteristic " $L$ " shape. Layers A and A1 are not distinguishable from each other, nor is there any evidence of leaflet formation. The border between the lateral geniculate nucleus and the perigeniculate nucleus is difficult to define and the medial interlaminar nucleus is generally not clearly separable from the main part of the nucleus. In spite of these striking abnormalities produced by the binocular enucleation, some aspects of the normal organization can still be recognized in the main part of the nucleus. The outer regions, close to the pia, within which the parvocellular $\mathrm{C}$ layers would normally form next to the optic tract, are made up of relatively small cells that tend to be elongated parallel to the surface as in the normal C laminae (Figs. 4 and 5). In contrast, the inner regions, which lie next to the thalamocortical radiations and which would normally form the generic " $\mathrm{A}$ " layers, are made up of larger cells that show no clear orientation, or an orientation perpendicular to the surface, and in this they resemble the normal A layers. In addition, the shape of the nucleus, although abnormal, resembles the normal shape insofar as the medial and caudal parts, which would normally form the binocular segment, are thicker than the lateral and rostral parts, which represent the monocular segment (Figs. 2 and 3). The cells also show the normal size gradient, being largest medially in the "binocular" segment. In some sections through the binocularly deafferented nucleus, the medial interlaminar and perigeniculate nuclei can be distinguished, but with difficulty. The medial interlaminar nucleus is identifiable in a few of the sections because of the relatively elongated cells that characterize this triangular zone (Figs. 2 and 3 ). The cells of the perigeniculate nucleus ( $P$ in Figs. 2 and 3 ) can be seen scattered among the fibers of the optic radiation. They do not form a clearly separate nucleus but, rather, extend as scattered cells from the rostral parts of the $A$ laminar region, into the poorly defined optic radiation. 


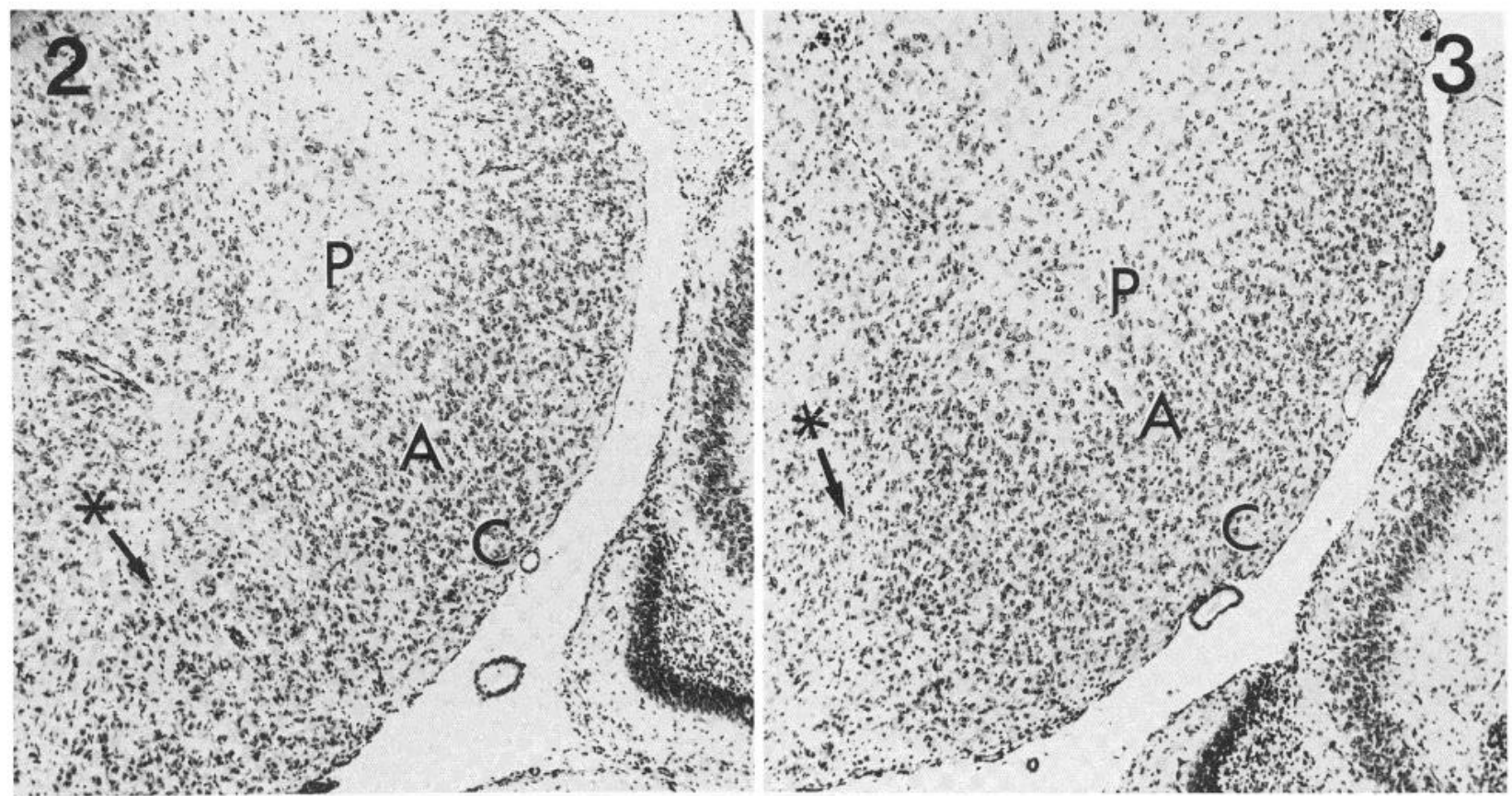

Figures 2 and 3 . Horizontal sections through the dorsal lateral geniculate nucleus of a ferret, binocularly enucleated on intrauterine day 28 , which survived 4 weeks postnatally; Niss method. $P, A$, and $C$ indicate the region of the perigeniculate nucleus, the generic $A$ layers, and the $C$ layers, respectively. The asterisk indicates the region of the poorly defined medial interlaminar nucleus. Rostral is up, and medial is to the left. Magnification; Figure 2: $\times 70 ;$ Figure 3: $\times 60$.
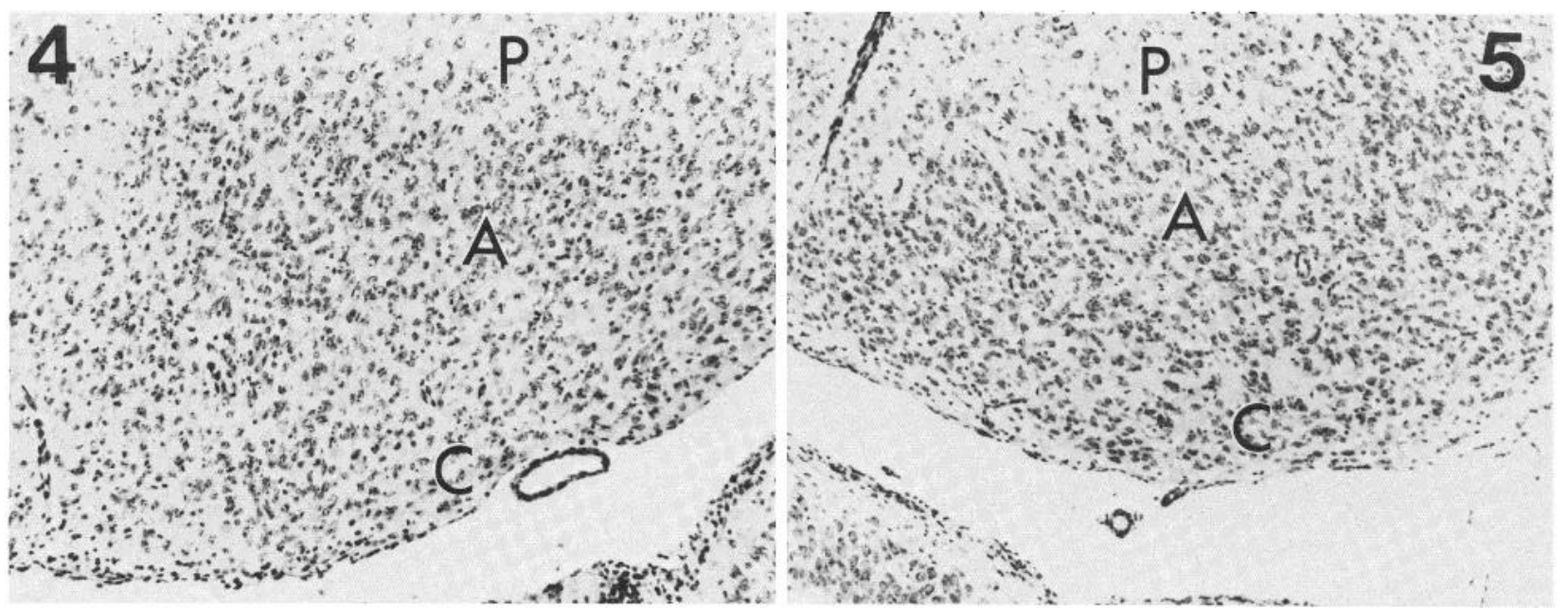

Figures 4 and 5. Higher magnification pictures of sections comparable to Figures 2 and 3 . Abbreviations are as in Figures 2 and 3 . Rostral is up. Medial is to the left for Figure 4, and to the right for Figure 5. Magnification $\times 90$.

\section{The lateral geniculate nucleus after a monocular enucleation}

Whereas the binocular enucleations demonstrate the aspects of geniculate differentiation that are entirely independent of retinal afferents, the monocular enucleations show the extent to which geniculate development depends upon two separate sets of afferents, one normally coming from each eye. Since the normal and the albino animals demonstrate rather different relationships, they will be described separately.

Normally pigmented animals. The effects of a monocular enucleation are similar in the ferrets and the mink, but since they are shown most clearly in the mink, we describe this animal first (enucleation on first postnatal day, $\left[{ }^{3} \mathrm{H}\right]$ proline injection at 10 months, final fixation 10 days later). The laminar structure of both lateral geniculate nuclei is well defined but abnormal, and the abnormal structure is clearly asymmetrical. The nucleus ipsilateral to the surviving eye is about $20 \%$ smaller in terms of its linear dimensions (mediolateral and dorsoventral) than the other nucleus. Figures 7 and 8 show that, in terms of the cellular structure revealed by the Nissl stain, the generic " $\mathrm{A}$ " layers can be distinguished from the $\mathrm{C}$ layers in each nucleus, but they do not show the basis on which one can distinguish layer A from layer A1 or identify a leaflet as opposed to a layer. The autoradiographic labeling, which is only faintly visible in Figures 7 and 8 , shows that all of the layers on each side except layer C3 nearest the optic tract receive retinal afferents, and we have named the surviving layers on this basis, in accordance with their retinal input. That is, we recognize two leaflets of layer $A 1$ on the side of the surviving eye (Fig. 8) and two leaflets of layer A on the other side (Fig. 7). Other features support this interpretation: although both nuclei show the wedge-shaped structure with a broad medial and a narrower lateral portion, contralateral to the surviving eye the nucleus is larger (see above) and the narrower "monocular" segment extends further rostrally and laterally than it does on the other side. Also, the 


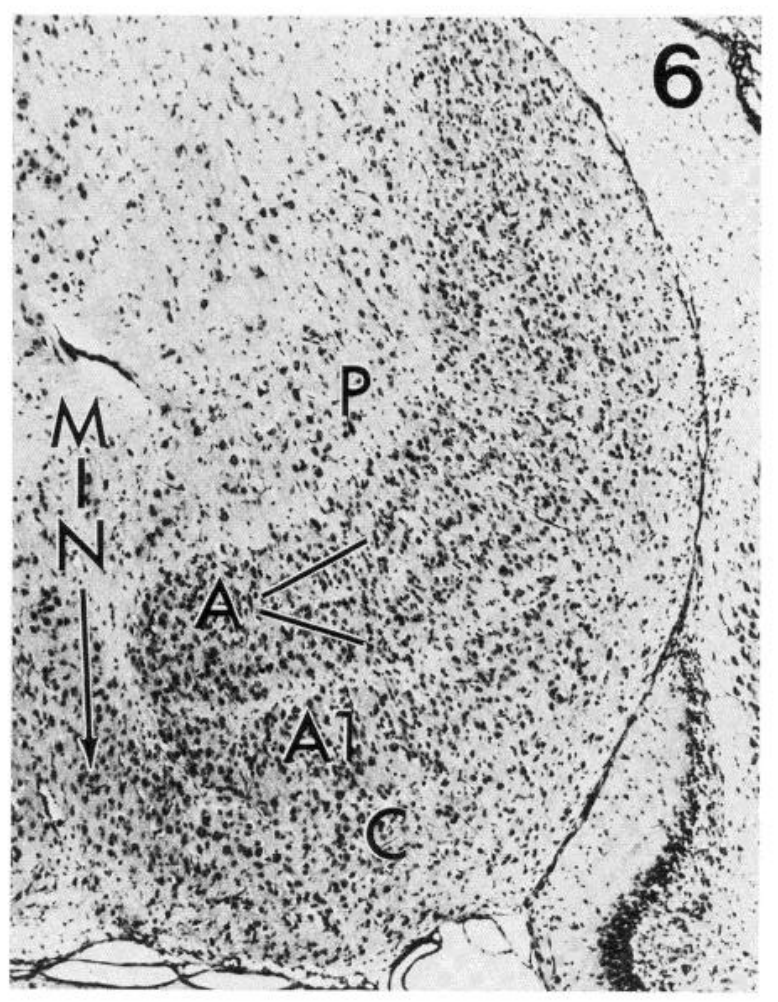

Figure 6. Horizontal section through the dorsal lateral geniculate nucleus of a 4-week-old normal ferret; Nissl method. Abbreviations are as in Figure 1. The two leaflets of layer A can be faintly discerned. Rostral is up and to the left; medial is to the left and down. Magnification $\times 50$.

cell size gradient is clearer on the side contralateral to the surviving eye. As in the normal animals, the leaflets of layer $A 1$ are less clearly separable than the leaflets of layer $A$. The magnocellular $C$ layer, which normally receives crossed afferents, is clearly identifiable on the side opposite the surviving eye (Fig. 7) but cannot be seen on the other side (Fig. 8).

The structure of the lateral geniculate nucleus is asymmetrical not only in terms of its laminar arrangements, but also in terms of the cell-free zones that separate the nucleus from the perigeniculate and medial interlaminar nuclei. On the side contralateral to the surviving eye these boundaries are essentially normal (Fig. 7). There is a well defined cell-free zone separating lamina A from the perigeniculate nucleus rostrally and from the medial interlaminar nucleus medially. The border between the medial interlaminar nucleus and the $\mathrm{C}$ laminae is less clear, as in a normal animal. In contrast to this, on the side of the surviving eye the boundaries are less distinct (Fig. 8). Cells are scattered irregularly between lamina A1 and the perigeniculate nucleus. The fibrous zone that so clearly defines the rostral border of the lateral geniculate nucleus in a normal animal is thin and is interrupted by these scattered cells. The border of the medial interlaminar nucleus is also poorly defined on this side, the nucleus being recognizable by its elongated cells, not by any cellfree border region.

The results illustrated in figures 7 and 8 for a monocular mink have been confirmed by observations of six ferrets in which one eye had been removed at birth (survival, 4 to 12 weeks). In the ferrets the Nissl preparations do not show the laminar structure as clearly as in the mink, but this difference is also seen in normal animals and is not related to the effects of the enucleation. The ferrets' geniculate layers can be readily identified when the retinogeniculate axons are labeled (see Fig. 9). Figure 9 shows the nucleus contralateral to the surviving eye after a neonatal enucleation and shows a rather heavy distribution of autoradiographic label, which largely obscures the Nissl picture. Lamina A is clearly defined, having two distinct leaflets, and layers $\mathrm{C}$ and $\mathrm{C} 2$ can be seen as well. The nucleus on the other side (not illustrated) shows the distinction between the two leaflets of layer A1 less clearly, but in all other respects these nuclei show the features we have described for the mink.

The geniculate structures that are innervated by the retinofugal fibers of the monocular animals represent more than a survival of only those structures that would normally have been innervated by the remaining eye. Thus, on the side of the surviving eye, the leaflets of layer A1 are thicker than normal in the medial part of the nucleus (the "binocular" parts) they also extend further laterally than do the normal leaflets of lamina A1, incorporating parts of the nucleus that resemble the normal monocular segment. In the mink these lateral regions were not labeled autoradiographically, suggesting either that in this animal not all parts of the eye were reached by the proline, or that these most lateral parts represent surviving portions of the denervated layer $A$ that were not invaded by the surviving axons but nonetheless fused with the lateral portion of layer A1. Since the
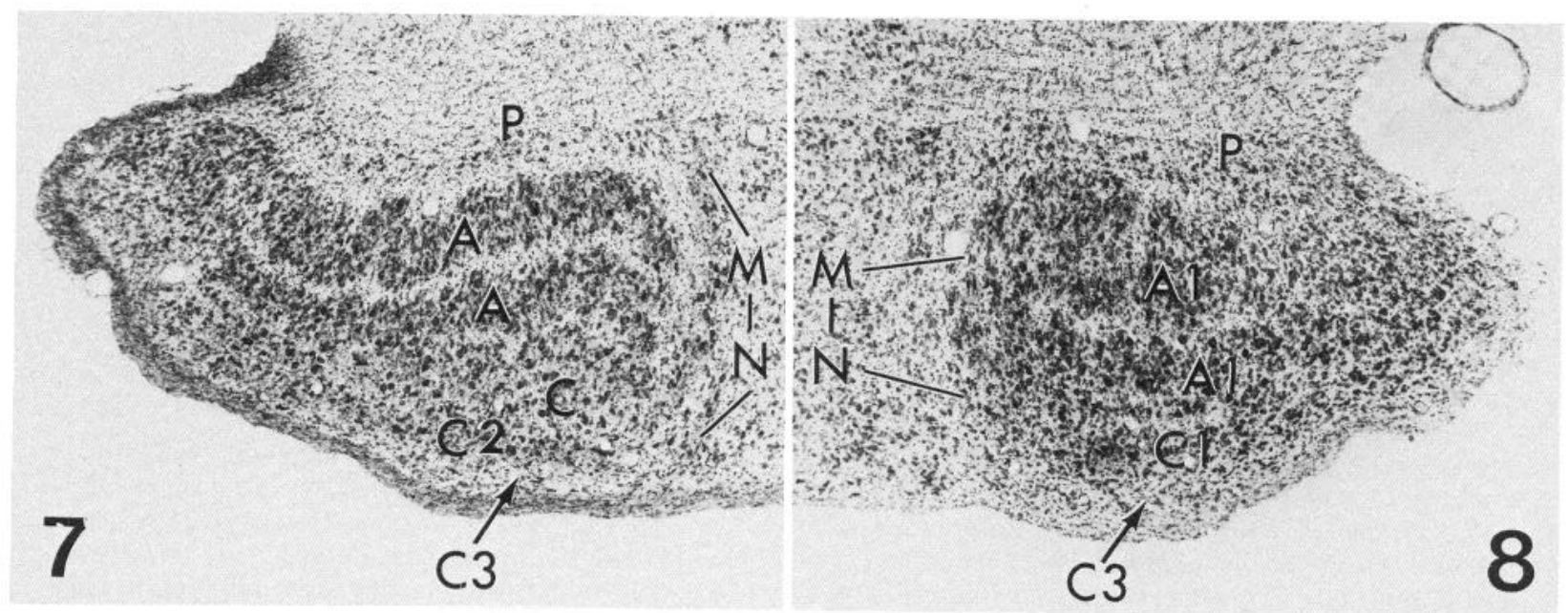

Figures 7 and 8. Horizontal sections through the dorsal lateral geniculate nucleus contralateral (Fig. 7) and ipsilateral (Fig. 8) to the surviving eye of a mink that had had a monocular enucleation on the day of birth and survived to maturity (10 months); autoradiographs show very light label and were counterstained using the Nissl method. Abbreviations are as in Figure 1. In Figure 7 layer A1 is missing, and in the caudal parts of the nucleus the magnocellular layer $\mathrm{C}(\mathrm{C})$ and the parvocellular layers $(\mathrm{C} 2$ and $\mathrm{C} 3)$ can be seen. In Figure 8 layer $\mathrm{A}$ is missing and so is the magnocellular layer $\mathrm{C}$. Rostral is up. Medial is to the right for Figure 7, and to the left for Figure 8. Magnification $\times 37$. 


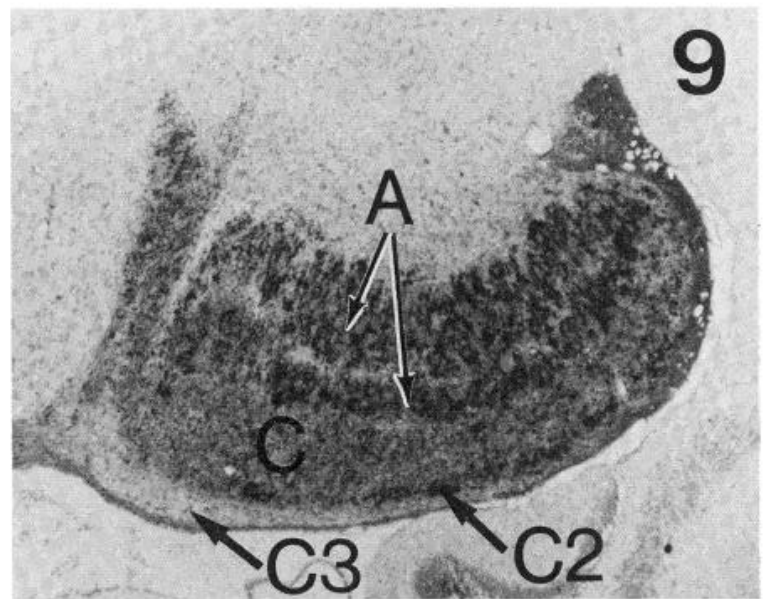

Figure 9. Horizontal section through the dorsal lateral geniculate nucleus contralateral to the surviving eye of a ferret that had had a monocular enucleation on the day of birth and survived for 3 months; the autoradiograph shows transport of $\left[{ }^{3} \mathrm{H}\right]$ proline from the surviving eye, lightly counterstained by the Nissl method. Abbreviations are as in Figure 7. Rostral is up, and medial is to the left. Magnification $\times 28$.

ferrets show a retinal innervation in this most lateral part of layer $\mathrm{A} 1$, we favor the first interpretation for the mink.

On the side opposite the surviving eye, layer $A$ is not markedly thickened, except that in some sections the most medial part of the inner leaflet curves posteriorly and wraps partially around the medial aspect of the outer leaflet, giving this most medial region a somewhat thickened appearance (Fig. 7). The magnocellular layer C, however, is particularly thickened in the binocular segment, and its characteristic, scattered, large cells occupy much of the region normally occupied by lamina A1, as though a part of the denervated layer A1 had been incorporated into the magnocellular $\mathrm{C}$ layer.

The monocular animals thus demonstrate the extent to which the shape, the boundaries, the cell sizes, and the laminar structure of the lateral geniculate nucleus are dependent for their normal development on retinal afferents. They confirm the conclusion based on the results of the binocular enucleations in showing that the characteristic wedge shape of the normal nucleus, with a broad binocular and a narrow monocular segment, is not dependent upon a binocular input. However, the overall size of the nucleus is dependent on retinal afferents, and there are clear differences between the crossed and the uncrossed afferents when each set is allowed to act on its own. Finally, these results suggest that the development of a normal complement of laminae is dependent on an interaction between afferents from both eyes. However, the monocular albino animals described below show that an almost normal set of geniculate laminae can be produced by retinal afferents from one eye only, with no binocular interaction.

Albino animals. The structure of the lateral geniculate nucleus of albino ferrets has been described fully by Cucchiaro and Guillery (1984), and a horizontal section through the nucleus is shown in Figure 10. Layers $A$ and $A 1$ are identifiable in this section on the basis of the autoradiographic label, but in other sections layer $A 1$ is significantly smaller than normal, is interrupted, or is not identifiable. Most of layer A1 receives crossed afferents and is continuous medially with layer $\mathrm{A}$. Smaller segments of layers $\mathrm{A} 1$ and $\mathrm{C} 1$ receive uncrossed afferents (asterisk in Fig. 10). They can be identified as patches free of label contralateral to an injected eye or as labeled patches (not shown) on the side of an injected eye. In most sections there is one such patch receiving ipsilateral afferents, but in some sections two or even three patches are identifiable. The characteristic leaflets are identifiable in lamina $\mathbf{A}$ and in some parts of lamina A1; the interlaminar zones are normal except in the medial parts of the nucleus where layers $A$ and $A 1$ fuse. The perigeniculate and medial interlaminar nuclei can be defined as in a normal animal.

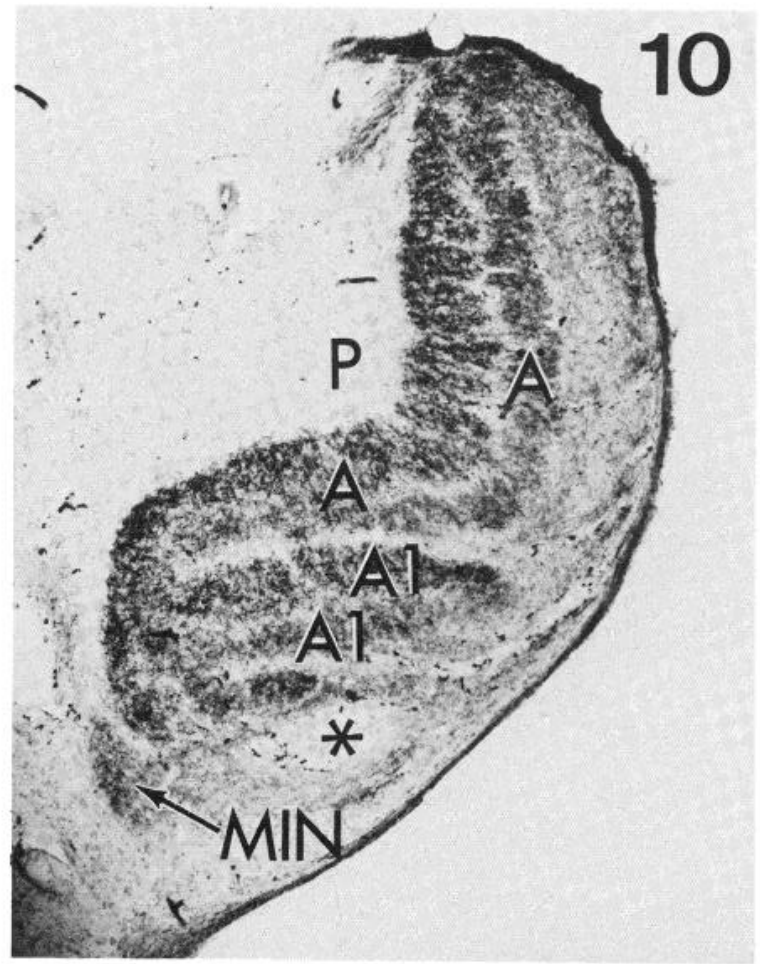

Figure 10. Horizontal section through the dorsal lateral geniculate nucleus of a normal albino ferret. The autoradiograph shows transport of $\left[{ }^{3} \mathrm{H}\right]$ proline from the contralateral eye. Rostral is up and to the left; medial is down and to the left. Abbreviations are as in Figure 1. The asterisk marks an ipsilaterally innervated cell group that may represent layer $\mathrm{A} 1$ or layer $\mathrm{C} 1$, or a fusion of the two. These patches were autoradiographically labeled on the other side (see the text). Magnification $\times 52$.

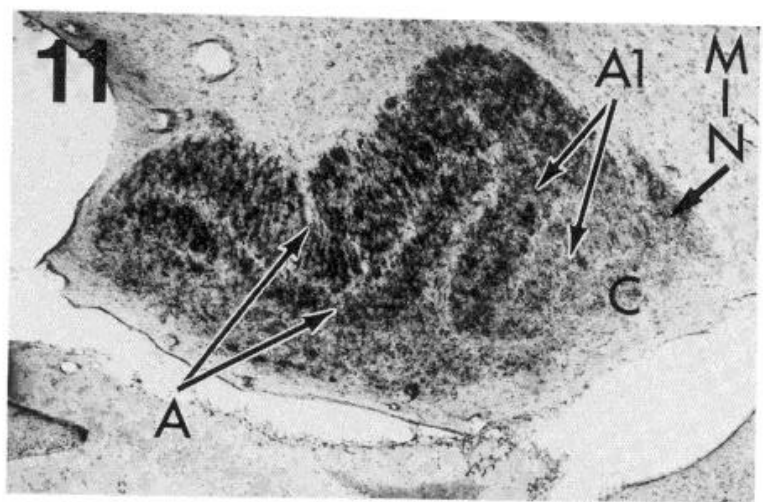

Figure 11. Horizontal section through the dorsal lateral geniculate nucleus contralateral to the surviving eye of an albino ferret monocularly enucleated on the day of birth and allowed to survive for 4 months. The autoradiograph, lightly counterstained with Nissl stain, shows transport of label from the surviving eye. Abbreviations are as in Figure 1. Rostral is up and to the left; medial is to the right and up. Note that there are no unlabeled patches in this nucleus comparable to that marked with an asterisk in Figure 10. Magnification $\times 40$.

After a monocular enucleation at birth and 4 to 28 weeks survival ( 10 animals), the nucleus contralateral to the surviving eye shows very few changes (Fig. 11). The small ipsilaterally innervated patches of layers A1 and C1 have disappeared, but in all other respects, the nucleus looks remarkably like that of a normal albino ferret. Layers $\mathrm{A}$ and $\mathrm{A} 1 \mathrm{can}$ be identified in approximately their normal albino relationships (cf. Fig. 10 and 11), and all parts of the nucleus receive a crossed innervation.

Ipsilateral to the surviving eye, the nucleus shows little architectonic differentiation and in a Nissl preparation is comparable to the 

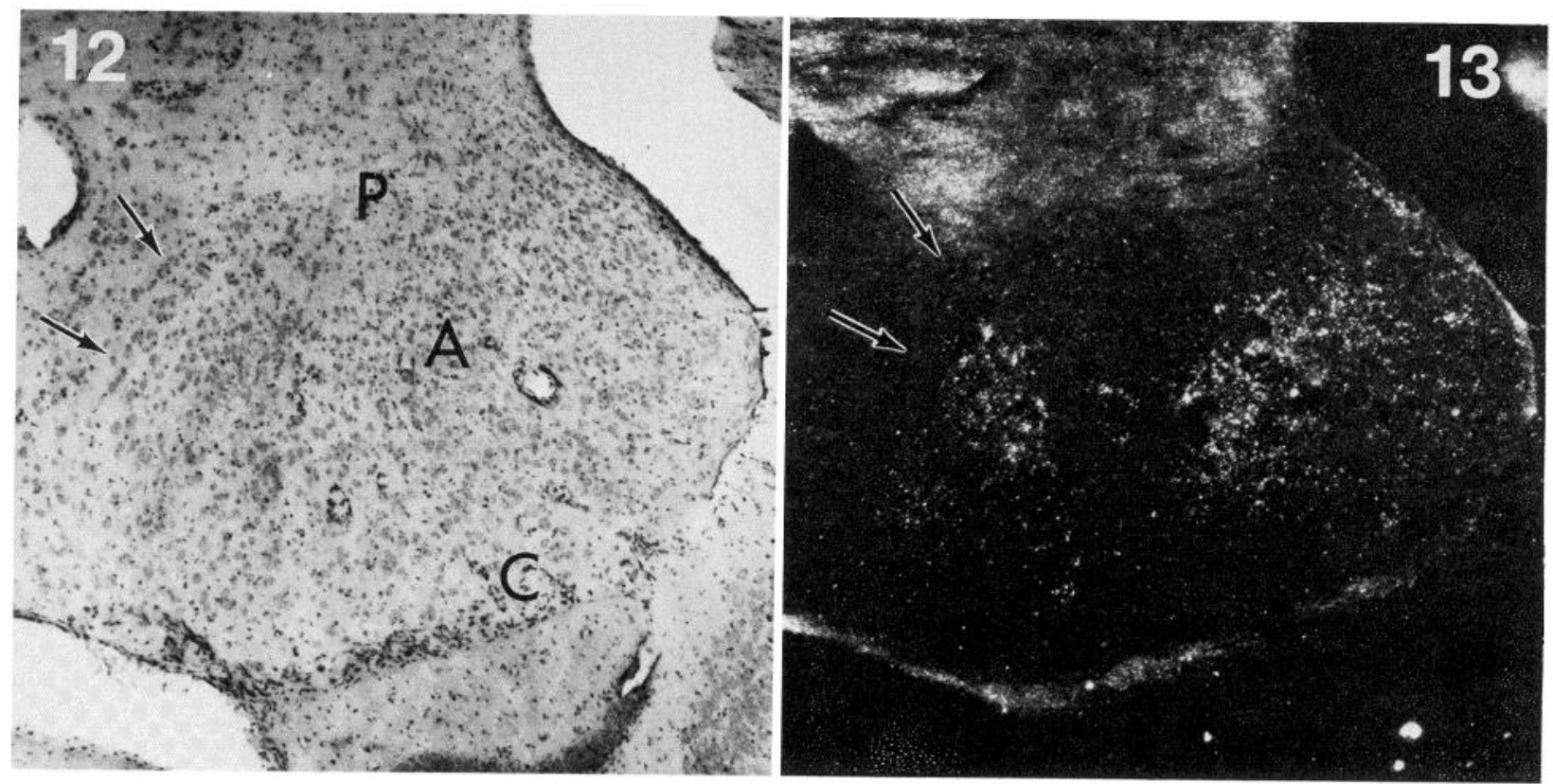

Figures 12 and 13. Horizontal section through the dorsal lateral geniculate nucleus ipsilateral to the surviving eye of an albino ferret monocularly enucleated on the day of birth and allowed to survive for 4 months. Figure 12 is a brightfield micrograph and Figure 13 is a darkfield micrograph of the autoradiographically labeled nucleus, showing the structure of the nucleus (Fig. 12) and the distribution of the uncrossed retinogeniculate fibers (Fig. 13). Labels are as in Figure 1. The arrows indicate the medial and rostral parts of the nucleus in both figures. Note that in Figure 13 the orientation of the neuronal perikarya, on the basis of which layers $\mathrm{A}$ and $\mathrm{C}$ can be differentiated, is not clearly shown. Magnification $\times 63$.

nucleus formed after a binocular enucleation (Fig. 12). The boundaries of the perigeniculate and medial interlaminar nuclei are poorly defined, and the laminar structure only shows the basic distinction between parvocellular $C$ layers near the tract and generic " $A$ " layers more rostrally. However, the autoradiographs show that there is an uncrossed retinal input to the nucleus (Figs. 13 and 14), which appears as small dense patches surrounded by more diffuse terminal label.

The ipsilateral projection does not reach all parts of the nucleus. The medial and rostral parts are essentially free of label. There are zones next to the medial interlaminar nucleus and next to the perigeniculate nucleus that are unlabeled, and there are other unla-

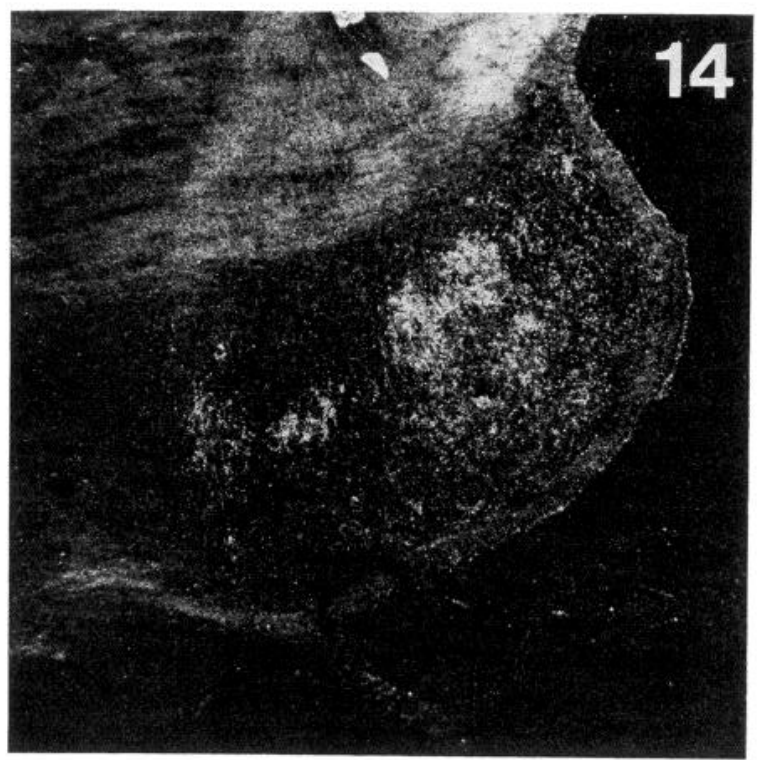

Figure 14. Darkfield micrograph comparable to Figure 13 , to show the patchy distribution of the uncrossed retinogeniculate fibers in another animal. Magnification $\times 50$. beled patches scattered in the nucleus. The most lateral third of the nucleus is somewhat more richly innervated than the rest of the nucleus, and in some of the sections it is possible to see an indication of two distinct leaflets here (weakly shown in Fig. 14). These leaflets are visible only in terms of retinal afferents; not in terms of the perikaryal distributions seen in a Nissl preparation.

This patchy labeling of the ipsilateral retinogeniculate component is relatively more extensive than the uncrossed label in a normal albino, but it has a distribution that would be produced if each of the small normal components expanded into the denervated portions but failed to reach them all. We do not regard this patchy labeling as an artifact of uptake or transport because the nucleus on the other side is heavily and evenly labeled and because the lateral parts of the nucleus, which are most commonly unlabeled in incomplete experiments, are well labeled. Also, the patchy pattern, which is seen repeatedly, is consistent with the known distribution of uncrossed fibers in albinos. The binocular enucleate animals have shown that geniculate cells can survive in the absence of a retinal input, and the geniculate areas that are not reached by the uncrossed afferents in the monocular albino animals would seem to confirm this.

Preliminary comparisons of cell sizes in the innervated and uninnervated regions suggest that in some sections the cells lying in a patch of retinal afferents are slightly larger than the surrounding cells. However, it is not possible to draw clear borders around the patches of fiber labeling, nor are the differences that one sees between the innervated and the uninnervated cells large or consistent. Since in all of the animals there are also systematic cell size differences (mediolateral and rostrocaudal) in the nucleus, we have not quantified the differences in cell sizes. A striking feature of the nucleus, in view of the dramatic effects that can be produced by retinal deafferentation at later stages, is that the cells in the uninnervated parts of the nucleus are not very much smaller than the others.

\section{Discussion}

The development of the geniculate region in the absence of retinal afferents. The dorsal lateral geniculate nucleus can develop its basic shape in the absence of all retinal afferents, forming a 
broad medial region that corresponds to the normal binocular segment, and a narrower lateral region where the monocular segment is normally seen. Also, some of the distinctions between the nucleus itself and the adjacent perigeniculate and medial interlaminar nuclei can form, although the relatively cell-free zones that normally separate these areas from each other fail to develop and the nuclei are poorly differentiated. Finally, some laminar differentiation occurs within the nucleus, but this does not lead to the formation of any of the cell-free interlaminar zones that provide the most obvious markers of laminar differentiation in a normal adult.

We have not addressed the quantitative aspects of geniculate development. Reducing the retinal input produces a nucleus that is smaller than normal and there are fewer large cells (see also Sugita and Otani, 1983). However, since preliminary cell counts have shown surprisingly high variabilities in normal and experimental animals, this report has been limited to the nonquantitativc foatures.

The structures of the lateral geniculate nucleus that can develop in the absence of retinal afferents have been described previously for genetically or experimentally produced anophthalmic mice (Cullen and Kaiserman-Abramof, 1976; Kaiserman-Abramof, 1983) or hamstcrs (Rhoades and Fish, 1983). A moderately well organized nucleus can develop with no retinal input. The extent to which the characteristic shape, borders, and laminar structure of the nucleus are influenced by retinal afferents is more strikingly demonstrable in the more complexly differentiated nucleus of the mustelids, but the basic observation, that a significant amount of differentiation can occur without retinal afferents, is the same in all of these species. In anophthalmic humans, too, although the shape of the nucleus is abnormal and its borders are poorly defined, the nucleus is preserved to some extent, and some segregation of cell groups according to size can be seen (Finkelstein, 1936; Duckworth and Cooper, 1966). However, for the human material there is no evidence about the stage at which the development of the retinofugal fibers failed, and there are reports (see Recordon and Griffiths, 1938) of a complete absence of the lateral geniculate nucleus. Some distinction between parvo- and magnocellular layers is seen in macaque monkeys following an early intrauterine binocular enucleation ( $P$. Rakic, unpublished observation).

Our results go beyond earlier accounts in showing the exterll 10 which the development of regional differences in the nucleus (laminar differences and mediolateral differences) are independent of retinal afferents. The contribution that other afferent systems may make to geniculate differentiation therefore need consideration. Nonvisual alferents that normally enter the lateral geniculate nucleus from the brainstem (Gilbert and Kelly, 1975; Leger et al., 1975; Hughes and Mullikin, 1984) are unlikely to play an important role unless they have a laminar distribution or terminate differentially in the monocular and binocular segments. Afferents that may be deviated into the nucleus by the early retinal deafferentation could play a role in the abnormal geniculate development, but since these afferents have no components corresponding to a monocular:binocular difference and do not normally form laminae in the thalamus, they are not likely to contribute to the development of the specific features of geniculate structure spared in the experimental animals. Electron microscopic studies of the nucleus after an early prenatal, binocular enucleation (Guillery et al., 1985) show none of the characteristic large axon terminals that specific afferent systems generally form in the thalamus (see Jones, 1981, for summary), suggesting that other specific afferents have not grown into the deafferented nucleus.

Tectogeniculate fibers that normally pass to the geniculate parvocellular C layers (Graybiel, 1972; Graham, 1977; Torrealba et al., 1981) could contribute to the laminar differentiation of the nucleus. It may thus prove of interest to define the laminar distribution of these fibers in the abnormal animals and to determine the stage at which they reach the nucleus. However, indirect evidence from normal ferrets suggests that the tectal fibers reach the lateral geniculate nucleus relatively late, during the second postnatal week (Cucchiaro and Guillery, 1984). The distinction between the A layers and the $\mathrm{C}$ layers is already recognizable before this in normal animals (Linden et al., 1981) and also after an early binocular enucleation (A. L. LaMantia and R. W. Guillery, unpublished observation), suggesting that the basic laminar differentiation seen in the enucleate animals is not dependent on a tectal input.

The extent to which corticogeniculate afferents influence geniculate development is not known. In the cat these afferents arise from several different cortical areas (Updyke, 1975, 1981; Gilbert and Kelly 1975; Raczkowski and Rosenquist, 1980, 1983), the projections are topographically mapped, and each has a characteristic laminar distribution in the lateral geniculate nucleus. They may thus play a major role in the preservation of geniculate structure when the retinal afferents are removed. The features that develop in the absence of retinal afferents must be regarded as representing the intrinsic capacities of the geniculocortical system, including the corticogeniculate and the geniculocortical pathways.

Varying the size of the retinal input. The monocular enucleations have produced four degrees of retinal deafferentation which extend from the condition contralateral to the normal eye of an albino animal at one extreme to that ipsilateral to the normal eye of an albino at the other. The two nuclei of a normally pigmented monocular animal lie in between.

The nucleus contralateral to the surviving eye of an albino animal receives quantitatively an almost normal complement of retinal afferents, but the afferents come from one eye, not from two. This experiment shows that the development of a full complement of geniculate layers, which appears to require fibers from each eye in a normal animal, can occur in an albino animal with afferents from one eye only and, therefore, without any binocular interactions. The critical factor in producing a nucleus having representatives of layers $A$ and $A 1$ may be simply the size of the remaining retinal input, or it may be that the input must have components from nasal as well as temporal retina. Binocular interactions are not needed (see below).

The pigmented monocular animals demonstrale that there is a difference between the crossed and the uncrossed pathways, and that this difference persists even after an early monocular enucleation. It is known that in other species an early removal of one eye produces an increased survival of ganglion cells in the other (e.g., Rakic and Riley, 1983; Williams et al., 1983) and that there is an increase in the number of uncrossed retinofugal axons (Jeffery, 1984). Nonetheless, the crossed pathway can sustain a larger and better differentiated nucleus than the uncrossed pathway, and this applies to the laminar structure of the nucleus itself and also to the cell-free borders of the medial interlaminar and perigeniculate nuclei. Again, it remains to be defined whether it is the total size of the retinal input that is relevant, the crossed being larger than the uncrossed, or whether there is a critical difference between other properties of the two components.

The nucleus ipsilateral to the surviving eye of an albino forret is barely distinguishable in a Nissl preparation from a completely deafferented nucleus. The autoradiographs demonstrate that the few surviving retinogeniculate fibers have a limited capacity for invading the lateral geniculate nucleus. Even when uninnervated areas of the nucleus are available, the uncrossed retinogeniculatc fibers seem unable to reach them. The curious interrupted patches of ipsilateral afferents seen in the albino ferrets are of particular interest. There is no reason for thinking that the ganglion cells giving rise to uncrossed fibers have a correspondingly patchy retinal distribution. Observations of normally reared albino ferrets (Cucchiaro, 1984) show a continuous distribution of such cells in the temporal retina, in agreement with earlier observations of Siamese cats (Stone et al., 1978, Cooper and Pettigrew, 1979). Since the segregation of crossed and uncrossed fibers starts some days after birth in a normal animal (Linden et al., 1981) and even later in the albinos (Cucchiaro and Guillery, 1984), it is unlikely that the patchy distribution is produced by an early, prenatal interaction between crossed and uncrossed afferents, the effects of which survive removal of the crossed fibers. However, it is possible that the patchy 
distribution would not be seen if one eye had been removed prenatally instead of postnatally. The experiment needs to be done, but since the difference between a prenatal and a postnatal enucleation is minor in the pigmented animals, we have no reason to think that the earlier enucleation will produce a different result in the monocular albino. At present we have no explanation for the patchy distribution of the uncrossed retinofugal fibers in the albino nucleus.

Competitive interactions. There are several situations in which an experimentally induced reduction of one set of axon terminals allows another set to expand, invading the territory vacated by this reduction (Lynch and Cotman, 1975; Hubel et al., 1977; Murphey and Lemere, 1984). Insofar as this interaction represents a restraint that in normal development prevents one set of axons from establishing a synaptic territory, one can regard the interaction as "competitive." Insofar as the vacated synaptic sites stimulate synaptic formation that would not have occurred normally, the interaction is not strictly competitive, but rather can be regarded as "cooperative," since one set of axons is helping to occupy synaptic sites that can no longer be occupied by the other set. The distinction is subtle and cannot always be easily established on experimental grounds, but it is likely to be an important distinction as one attempts to define the events that occur in normal development. Furthermore, of course, wherever one set of axons has a consistent, specifiable terminal distribution, distinguishing it from the other set, one needs to look for interactions other than competition to account for the adult form.

Farly monocular enucleations have been extensively studied in several different species. The surviving retinofugal fibers can invade the regions that are denervated, or fail to withdraw from regions that would normally have been vacated during development (Guillery, 1972; Lund et al., 1973; Hickey, 1975; Lund and Lund, 1976; Lent and Rocha-Miranda, 1978; Robson et al., 1978; Sanderson et al., 1978; Finlay et al., 1979; Land and Lund, 1979; Godemont et al., 1980; Jeffery, 1984; So et al., 1984). The second change, associated with the earliest enucleations, is accompanied by an increase in the number of retinal ganglion cells or retinofugal fibers in the surviving eye (Sengelaub and Finlay, 1981; Rakic and Riley, 1983; Sengelaub et al., 1983; Williams et al., 1983; Jeffery, 1984). However, it should be noted that, whereas the extrasynaptic territory produced by the removal of one eye is, in principle, doubled, the number of ganglion cells that is "saved" is generally less than the number that would have developed in the removed eye.

The changes we have seen in the lateral geniculate nucleus after a monocular enucleation demonstrate that the parcelling of synaptic territories within the nucleus is not based upon a simple, competitive interaction between the two sets of retinal afferents, each capable of innervating all parts of the nucleus. Rather, it appears that each set of afferents has a prescribed terminal distribution and a limited capacity to innervate extra territory should this become available. That is, the normal developmental sequence is rigidly choreographed, and this is only modified when extra synaptic territories are vacated. This is strikingly demonstrated by the surviving uncrossed component of the monocular albino ferrets, which develops its characteristic patchy distribution and fails to invade the whole nucleus, and it is also shown by the marked asymmetry of the nucleus in the normally pigmented monocular animals (see also Sanderson et al., 1978; Godemont et al., 1980; Heumann and Rabinowicz, 1980); The fact that, normally, nasal ganglion cells go to one set of geniculate layers and temporal ganglion cells go to another set and that they do this cven in a onc cycd animal (sce also Casagrande and Brunso-Bechtold, 1984) certainly points to aspects of geniculate development that define terminal distributions without competitive interactions between the two sets of retinal afferents.

The development of interlaminar zones. Within the lateral geniculate rogion of a normal animal there are cell-free zones between many of the functionally distinct retinal maps. These are seen as the interlaminar zones or as the border zones of the lateral geniculate nucleus. Also, there are cell-free zones where a single map is interrupted, as in the representation of the optic disc (see Kaas et al., 1972) or between the segments of the abnormal lamina A1 in albino ferrets or Siamese cats (Guillery and Kaas, 1971; Cucchiaro and Guillery, 1984). Corticogeniculate axons tend to grow into these cell-free zones (Guillery, 1967; Updyke, 1975; Montero and Guillery, 1978) either on their way to other regions or as a terminal plexus, and retinal terminals tend to keep out of these zones. Even though the interlaminar zones represent a concentration of nonretinal afferents, their development depends upon the presence of the retinal afferents. When no retinal afferents are present, no interlaminar zones develop (see also Brunso-Bechtold and Casagrande, 1981). ${ }^{4}$ When only one sel of relinal afferents is present, interlaminar zones develop between the leaflets of the surviving A layers in the mustelids, and develop between the magno- and parvocellular layers of Old World monkeys (Rakic, 1981), but interlaminar zones do not develop within the parvocellular zone of the monkey.

The difference between the development of the interlaminar zones in the monkey and in mustelids is of some interest. In mustelids, two types of interlaminar zones are recognizable: those separating layers $A$ and $A 1$ from adjacent regions, and those separating neighboring leaflets within the generic $A$ layers. The leaflets of the normal animals represent a segregation of on-center from off-center cells (LeVay and McConnel, 1982; Stryker and Zahs, 1983), and it would seem likely that the segregation of these functionally distinct leaflets follows a normal developmental course in the monocular animals. This is in contrast to the situation seen in Old World monkeys. Schiller and Malpeli (1978) have shown that, in the monkey, the parvocellular layers are also divided into leaflets, which also represent a segregation of on-center from off-center cells, and thcsc lcaflcts are also separated by interlaminar zones. Rakic (1981) has shown that, after an early monocular enucleation in a monkey, this leaflet formation fails. The parvocellular layer of the monocular monkey is seen as a single uninterrupted layer. ${ }^{5}$

We do not know the details of the developmental changes leading to leaflet formation in monkeys and mustelids. However, the monocular development provides some suggestive clues. In both forms the interlaminar zones which normally separate cell groups innervated by the same eye (e.g., the leaflets of layer A in mustelids, the two-three interlaminar zone in monkeys) can develop normally with a monocular innervation, as might be expected. It is the interlaminar zones that normally lie between cell groups innervated by different eyes that fail to develop in the monocular animals. The formation of the parvocellular leaflets in a normal monkey involves an alternation of left eye and right eye afferents in addition to a segregation of offcenter from on-center cells. There is no reason for thinking that this latter functional segregation does not occur in the monocular monkeys (the point bears investigation), but it seems that in the monkey this segregation by itself does not lead to the formation of an interlaminar zone, presumably because the normal developing system relies on the binocular clues, which are normally available within the parvocellular zone.

The difference between the development of segregated on-center and off-center leaflets in monkeys and mustelids is of interest because it draws attention to the different types of laminar segregation involved in geniculate development. Also, of course, it serves to illustrate the difficulty of finding rules that may prove applicable to geniculate development in general.

${ }^{4}$ It is of interest to note that, in a ferret, the interlaminar zone between layers $A$ and $A 1$ appears before the laminar segregation of retinal afferents is complete, suggesting that the final segregation of the retinal afferents may, in turn, be influenced by the cortical afferents.

${ }^{5}$ However, Moskowitz and Noback (1962) have described a subdivision of the parvocellular zone in congenital unilateral anophthaimia in man. Since one does not know the stage at which ocular development failed, a direct comparison between these results and those seen in experimental monkeys is not possible. 


\section{References}

Brunso-Bechtold, J. K., and V. A. Casagrande (1981) Effect of bilateral enucleation on the development of layers in the dorsal lateral geniculate nucleus. Neuroscience 2: 589-597.

Casagrande, V. A., and J. K. Brunso-Bechtold (1985) Development of lamination in the lateral geniculate nucleus: Critical factors. In Advances in Neural and Behavioral Development, N. Aslin, ed., Vol. 1, Ablex Publishing Corp., Norwood, NJ, in pres,.

Conway, J. L., and P. H. Schiller (1983) Laminar organization of tree shrew dorsal lateral geniculate nucleus. J. Neurophysiol. 50: 1330-1342

Cooper, M. L., and J. D. Pettigrew (1979) The retinothalamic pathways in Siamese cats. J. Comp. Neurol. 187: 313-348.

Cucchiaro, J., (1984) The retinal origin and geniculate termination of the optic pathways in normal and albino ferrets: a developmental study. Ph.D Thesis. University of Chicago.

Cucchiaro, J., and R. W. Guilery (1984) The development of the retinogeniculatc pathways in normal and albino ferrets. Proc. R. Soc. Lond. (Biol.) 223: $14 \uparrow-164$

Cullen, M. J., and R. I. Kaiserman-Abramof (1976) Cytological organization of the dorsal lateral geniculate nuclei in mutant anophthalmic and postnatally enucleated mice. J. Neurocytol. 15: 407-424.

Duckworth, T., and E. R. A. Cooper (1966) A study of anophthalmia in an adult. Acta. Anat. 63: 509-522

Finkelstein, F. E. (1936) Uber zwei Fälle von Anophthalmus congenitus mit besonderer Berücksichtigung der zentralen optischen Bahnen. Schweiz. Arch. Neurol. Psychiatr. 37: 15-52.

Finlay, B. L., K. G. Wilson, and G. E. Schneider (1979) Anomalous ipsilateral retinotectal projections in Syrian hamster with early lesions: Topography and functional capacity. J. Comp. Neurol. 183: 721-740.

Gilbert, C. D., and J. P. Kelly (1975) The projections of cells in different layers of the cat's visual cortex. J. Comp. Neurol. 163: 81-106

Godement, P., P. Saillour, and M. Imbert (1980) The ipsilateral optic pathway to the dorsal lateral geniculate nucleus and superior colliculus in mice with prenatal or posinalal loss of one eye. J. Comp. Neurol. 190: 611-626.

Graham, J. (1977) An autoradiographic study of the efferent connections of the superior colliculus in the cat. J. Comp. Neurol. 173: 629-654.

Graybiel, A. M. (1972) Some extrageniculate visual pathways in the cat Invest. Ophthalmol. 11: 322-332.

Guillery, R. W. (1967) Patterns of fiber degeneration in the dorsal lateral geniculate nucleus following lesions in the visual cortex. J. Comp. Neurol. 130: 197-221.

Guillery, R. W. (1969) The organization of synaptic interconnections in the laminae of the dorsal lateral geniculate nucleus of the cat. Z. Zellforsch 96: $1-38$.

Guillery, R. W. (1970) The laminar distribution of retinal fibers in the dorsal lateral geniculate nucleus of the cat: A new interpretation. J. Comp. Neurol. 138: 339-368.

Guillery, R. W. (1971) An abnormal retinogeniculate projection in the albino ferret (Mustelo furo). Brain Res. 33: 482-485.

Guillery, R. W. (1972) Experiments to determine whether retinogeniculate axons can form translaminar collateral sprouts in the lateral geniculate nucleus of the cat. J. Comp. Neurol. 146: 407-420.

Guillery, R. W. (1979) A speculative essay on geniculate lamination and its development. Prog. Brain Res. 51: 403-418.

Guillery, R. W. and J. H. Kaas (1971) A study of normal and congenitally abnormal retinogeniculate projections in cats. J. Comp. Neurol. 143: 73100.

Guillery, R. W., and M. D. Oberdorfer (1977) A study of fine and coarse retinofugal axons terminating in the geniculate $\mathrm{C}$ laminae and in the medial interlaminar nucleus of the mink. J. Comp. Neurol. 176: 515-526.

Guillery, R. W., M. Ombrellaro, and A. L. La Mantia (1985) The geniculate and geniculocortical organization that develops in the abscncc of retinal afferents. Dev. Brain Res., in press.

Heumann, D., and T. H. Rabinowicz (1980) Postnatal development of the dorsal lateral geniculate nucleus in the normal and albino mouse. Exp. Brain Res. 39: 75-85

Hickey, T. L. (1975) Translaminar growth of axons in the kitten dorsal lateral geniculate nucleus following removal of one eye. J. Comp. Neurol. 161. 359-382.

Hickey, T. L., and R. W. Guillery (1974) An autoradiographic study of retinogeniculate pathways in the cat and fox. J. Comp. Neurol. 156: 239254.

Hubel, D. H., T. N. Wiesel, and S. LeVay (1977) Plasticity of ocular dominance columns in monkey striate cortex. Philos. Trans. R. Soc. Lond. (Biol.) 278. $377-409$.
Hughes, H. C., and W. H. Mullikin (1984) Brainstem afferents to the lateral geniculate nucleus of the cat. Exp. Brain Res. 54: 253-258.

Jeffery, G. (1984) Retinal ganglion cell death and terminal field retraction in the developing visual system. Dev. Brain Res. 13: 81-96.

Jones, E. G. (1981) Functional subdivisions and synaptic organization of the mammalian thalamus. Int. Rev. Physiol. 25: 173-245.

Kaas, J. H., R. W. Guillery, and J. M. Allman (1972) Some principles of organization in the dorsal lateral geniculate nucleus. Brain Behav. Evol. 6: 253-299.

Kaiserman-Abramof, I. R. (1983) Intrauterine enucleation of normal mice mimics a structural compensatory response in the geniculate of eyeless mutant mice. Brain Res. 270: 149-153.

Land, P. W., and R.D. Lund (1979) Development of the rat's uncrossed retinotectal pathway and its relation to plasticity studies. Science 205: 698-700.

Leger, L., K. Sakai, D. Salvert, M. Touret, and M. Jouvet (1975) Delineation of dorsal lateral geniculate afferents from the cat brainstem as visualized by the horseradish peroxidase technique. Brain Res. 93: 490-496.

Lennie, P. (1980) Parallel visual pathways. A review. Vision Res. 20: 561594.

Lent, R., and C. E. Rocha-Miranda (1978) Aberrant retinofugal projections in the opossum after eye enucleation and tectal lesion. In Opossum Neurohiology, C. E. Rocha-Miranda and R. Lent, eds., pp. 217-250, Academia Brasiliera de Ciencias, Rio de Janeiro.

LeVay, S., and S. K. McConnel (1982) On and off layers in the lateral geniculate nucleus of the mink. Nature 300: 350-351.

Linden, D. C., R. W. Guillery, and J. Cucchiaro (1981) The lateral geniculate nucleus of the normal ferret and its postnatal development. J. Comp. Neurol. 203: 189-211.

Lund, R. D., and J. S. Lund (1976) Plasticity in the developing visual system: The effects of retinal lesions made in young rats. J. Comp. Neurol. 169: 133-154.

Lund, R. D., T. S. Cunningham, and J. D. Lund (1973) Modified optic projections after unilateral eye removal in young rats. Brain Behav. Evol. 8: $51-72$.

Lynch, G., and C. Cotman (1975) The hippocampus as a model for studying anatomical plasticity in the adult brain. In The Hippocampus, R. L. Isaacson and K. H. Pribram, eds., Vol. 1, pp. 123-154, Plenum Press, New York.

Mason, C. A., and J. A. Robson (1979) Morphology of retino-geniculate axons in the cat. Neuroscience 4: 79-98.

Montero, V. M., and R. W. Guillery (1978) Abnormalities of the corticogeniculate pathway in Siamese cats. J. Comp. Neurol. 179: 1-12.

Moskowitz, N., and C. R. Noback (1962) The human lateral geniculate body in normal development and congenital unilateral anophthalmia. J. Neuropathol. Exp. Neurol. 21: 377-382.

Murphey, R. K., and C. A. Lemere (1984) Competition controls the growth of an identified axonal arborization. Science 224: 1352-1355

Raczkowski, D., and A. C. Rosenquist (1980) Connections of the parvocellular $C$ laminae of the dorsal lateral geniculate nucleus with the visual cortex in the cat. Brain Res. 199: 447-451.

Raczkowski, D., and A. C. Rosenquist (1983) Connections of the multiple visual cortical areas with the lateral posterior pulvinar complex and adjacent thalamic nuclei in the cat. J. Neurosci. 3: 1912-1942.

Rakic, P. (1981) Development of visual centers in the primate brain depends on binocular competition before birth. Science 214: 928-931.

Rakic, P., and K. P. Riley (1983) Regulation of axon number in primate optic nerve by prenatal binocular competition. Nature 305: 135-137.

Recordon, E., and G. M. Griffiths (1938) A case of primary bilateral anophthalmia (clinical and histological report). Br. J. Ophthalmol. 22: 353-360.

Rhoades, R. W. and S. E. Fish (1983) Bilateral enucleation alters visual callosal but not corticotectal or corticogeniculate projections in hamsters. Exp. Brain Res. 51: 451-464.

Robson, J. A., C. A. Mason, and R. W. Guillery (1978) Terminal arbors of axons that have formed abnormal connections. Science 201: 635-637.

Rodieck, R. W. (1979) Visual pathways. Annu. Rev. Neurosci. 2: 193-225.

Rogers, A. W. (1979) Techniques of Autoradiography, Elsevier-North Holland Publishing Co., Amsterdam

Sanderson, K. J. (1974) Lamination of the dorsal lateral geniculate nucleus of the weasel (Mustelidea), raccoon (Procyonidae) and fox (Canidae) families. J. Comp. Neurol. 153: 239-266.

Sanderson, K. J., and J. H. Kaas (1974) Thalamocortical interconnections of the visual system of the mink. Brain Res. 70: 139-143.

Sanderson, K. J., R. W. Guillery, and R. M. Shackelford (1974) Congenitally abnormal visual pathways in mink (Mustela vison) with reduced retinal pigment. J. Comp. Neurol. 154: 225-248. 
Sanderson, K. J., L. J. Pcarson, and P. G. Dixon (1978) Altered retinal projections in bushtailed possum, Trichosurus vulpecula, following removal of one eye. J. Comp. Neurol. 180: 841-868.

Schiller, P. H., and J. G. Malpeli (1978) Functional specificity of lateral geniculate nucleus laminae of the rhesus monkey. J. Neurophysiol. 41: $788-797$

Sengelaub, D. R., and B. L. Finlay (1981) Early removal of one eye reduces normally occurring cell death in the remaining eye. Science 213: 573-574.

Sengelaub, D. R., M. S. Windrem, and B. L. Finlay (1983) Increased cell number in the adult hamster retinal ganglion cell layer after early removal of one eye. Exp. Brain Res. 52: 269-276.

Sherman, S. M., and P. D. Spcar (1982) Organization of visual pathways in normal and visually deprived cats. Physiol. Rev. 62: 738-855.

So, K. F., H. H. Woo, and L. S. Jen (1984) The normal and abnormal postnatal development of retinogeniculate projections in golden hamsters: An anterograde horseradish peroxidase tracing study. Dev. Brain Res. 12: 191205.

Stone, J., J. E. Campion, and J. Leicester (1978) The nasotemporal division of the retina in the Siamese cat. J. Comp. Neurol. 180: 783-798.

Stone, J., B. Dreher, and A. Leventhal (1979) Hierarchical and parallel mcchanisms in the organization of the visual cortex. Brain Res. Rev. 1 345-394.

Stryker, M. P., and K. R. Zahs (1983) On and off sublaminae in the lateral geniculate nucleus of the ferret. J. Neurosci. 3: 1943-1951.

Sugita, S., and K. Otani (1983) Quantitative analysis of the lateral geniculate nucleus in the mutant microphthalmic rat. Exp. Neurol. 82: 413-423.

Torrealba, F., G. D. Partlow, and R. W. Guillery (1981) Organization of the projection from the superior colliculus to the dorsal lateral geniculate nucleus of the cat. Neuroscience 6: 1341-1360.

Updyke, B. V. (1975) Patterns of projections of cortical areas 17,18 and 19 onto the laminae of the dorsal lateral geniculate nucleus in the cat. J. Comp. Neurol. 163: 377-396.

Updyke, B. V. (1981) Projections from visual areas in the middle suprasylvian sulcus onto the lateral posterior complex and adjacent thalamic nuclei in cat. J. Comp. Neurol. 201: 477-506.

Williams, R. W., M. J. Bastiani, and L. M. Chalupa (1983) Loss of axons in the cat optic nerve following fetal unilateral enucleation: An electron microscopic analysis. J. Neurosci. 3: 133-144

Wilson, J. R., and A. E. Hendrickson (1981) Neuronal and synaptic structure of the dorsal lateral geniculate nucleus in normal and monocularly deprived Macaca monkeys. J. Comp. Neurol. 197: 517-539. 